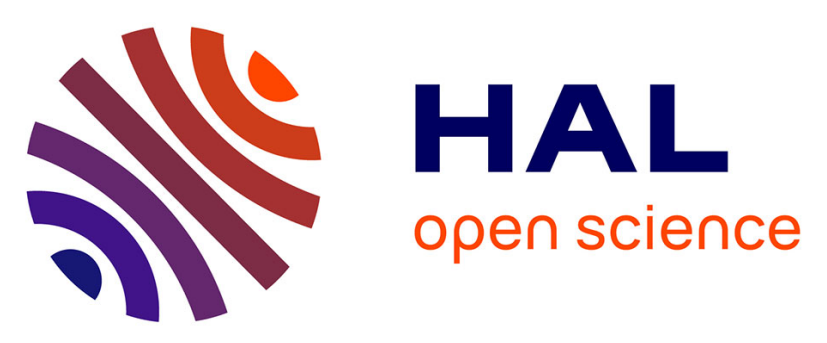

\title{
Anemia response and safety to epoetin-beta treatment in patients with neoadjuvant therapy prior to primary digestive tract tumor surgery
}

Antonio Gómez, Mercedes Salgado, Manuel Valladares-Ayerbes, Mónica Jorge, Ana Carballo, Sonia Candamio, Enrique Castro, Rafael López

\section{To cite this version:}

Antonio Gómez, Mercedes Salgado, Manuel Valladares-Ayerbes, Mónica Jorge, Ana Carballo, et al.. Anemia response and safety to epoetin-beta treatment in patients with neoadjuvant therapy prior to primary digestive tract tumor surgery. Cancer Chemotherapy and Pharmacology, 2009, 66 (3), pp.567-573. 10.1007/s00280-009-1197-0 . hal-00552483

\section{HAL Id: hal-00552483 \\ https://hal.science/hal-00552483}

Submitted on 6 Jan 2011

HAL is a multi-disciplinary open access archive for the deposit and dissemination of scientific research documents, whether they are published or not. The documents may come from teaching and research institutions in France or abroad, or from public or private research centers.
L'archive ouverte pluridisciplinaire HAL, est destinée au dépôt et à la diffusion de documents scientifiques de niveau recherche, publiés ou non, émanant des établissements d'enseignement et de recherche français ou étrangers, des laboratoires publics ou privés. 


\title{
Anemia response and safety to epoetin-beta treatment in patients with neoadjuvant therapy prior to primary digestive tract tumor surgery
}

\author{
Antonio Gómez • Mercedes Salgado • Manuel Valladares-Ayerbes • \\ Mónica Jorge • Ana Carballo • Sonia Candamio • Enrique Castro • \\ Rafael López
}

Received: 29 August 2009/Accepted: 26 November 2009/Published online: 12 December 2009

(C) Springer-Verlag 2009

\begin{abstract}
Purpose Anemia is common during anticancer treatment. This study aimed to evaluate the response and safety of treatment with epoetin-beta (EB) in patients with neoadjuvant therapy prior to primary digestive tract tumor surgery.

Patients and methods In this open-label, single-arm study, patients $(n=22)$ with hemoglobin $(\mathrm{Hb})$ levels below $11 \mathrm{~g} / \mathrm{dl}$ who received epoetin-beta $450 \mathrm{IU} / \mathrm{kg}$ (30,000 IU) weekly until the hemoglobin level reached $12 \mathrm{~g} / \mathrm{dl}$.
\end{abstract}

A. Gómez $(\bowtie) \cdot$ A. Carballo · S. Candamio Servicio Oncología Radioterápica, Hospital Clínico Universitario Santiago de Compostela, Travesia Choupana S/N, 15706 Santiago de Compostela, Spain

e-mail: antonio.gomez.caamano@sergas.es;

pilarfrontelo@gmail.com

M. Salgado

Servicio Oncología Médica, Complejo Hospitalario de Orense, Orense, Spain

M. Valladares-Ayerbes

Servicio Oncología Médica, Complejo Hospitalario de La

Coruña, La Coruña, Spain

M. Jorge

Servicio Oncología Médica, Complejo Hospitalario de Vigo,

Vigo, Spain

E. Castro

Servicio de Oncología Radioterápica, Complejo Hospitalario de Orense, Orense, Spain

R. López

Servicio Oncología Médica, Hospital Clínico Universitario

Santiago de Compostela, Santiago de Compostela, Spain
Results After treatment with EB, a mean absolute increment of $2.6 \mathrm{~g} / \mathrm{dl}$ was attained. The mean hemoglobin values during the study were pretreatment $10.1 \mathrm{~g} / \mathrm{dl}$, half-way through treatment $12.3 \mathrm{~g} / \mathrm{dl}, 4$ weeks after concomitant radiochemotherapy $12.7 \mathrm{~g} / \mathrm{dl}$, the week prior to surgery $12.5 \mathrm{~g} / \mathrm{dl}$, and after surgery $10.9 \mathrm{~g} / \mathrm{dl}$. No patient required transfusion before or after surgery. The probability or risk of postoperative complications was $27.3 \%$, and included one rectovaginal fistula, one parastomal hernia, one case of ileus and two surgical wound infections. In this series, downstaging was observed in $81.8 \%$ of patients, and downsizing in $90.9 \%$. Most interestingly, histopathological complete response rate was achieved by $18.2 \%$.

Conclusions Epoetin-beta (EB) treatment in our series of patients with digestive malignancies subjected to neoadjuvant radiochemotherapy proved effective and safe, avoiding the need for transfusion during surgery.

Keywords Anemia $\cdot$ Epoetin-beta .

Intestinal tract tumors · Neoadjuvant therapy

\section{Introduction}

Anemia is a common complication in patients with cancer as a result of the underlying disease, and is frequently exacerbated by the effects of antitumor therapy [1, 2]. In fact, this hematologic deficiency is detected in two out of three patients with gastrointestinal/colorectal cancer patients receiving established chemotherapy [2], since pyrimidine- and platinum-containing regimens have direct myelosuppressive effects [3]. This condition not only has a profound impact on quality of life (QoL) [4], but it is also been associated with poor treatment outcome and overall survival $[5,6]$. 
Preoperative chemoradiotherapy of the digestive tract improves local control and reduces toxicity [7, 8] in comparison to postoperative treatment. Thus, an exploratory analysis of complete and intermediate pathologic response exhibited improved disease-free survival (DFS) in colorectal patients [9] and other studies have highlighted the importance of tumor regression as a predictor of DFS in patients with esophageal carcinoma [10].

This neoadjuvant approach has also produced encouraging downstaging rates and has been found to facilitate complete resection and sphincter saving in distal rectal cancer with acceptable toxicity [11]. However, preoperative chemotherapy may induce or deepen preexisting anemia and may counteract the beneficial effects of neoadjuvant treatment, as has been shown for locally advanced esophagogastric cancer [12].

Therefore, anemia correction is been used to predict and improve clinical benefit to cancer therapy. A recent study showed that in rectal cancer patients receiving neoadjuvant treatment, anemia is able to predict clinical response (DFS) to antitumor therapy [13]. In fact, the level of $\mathrm{Hb}$ influence the percentage of patients with clinical downstaging, significantly favoring those with $\mathrm{Hb}>12$. In another report, rectal cancer patients with normal hemoglobin during chemoradiotherapy achieved better tumor response, less local recurrence, and improved overall survival when compared with anemic patients, independently of radiologic $\mathrm{T}$ stage, suggesting that correcting anemia may improve tumor response and oncologic outcome [14].

Several reports have confirmed that epoetin-beta (EB), a recombinant human erythropoietin, is effective increasing $\mathrm{Hb}$ levels, reducing transfusion requirements and improving QoL of patients with cancer-related anemia [15-18]. Despite recent concerns regarding the safety of erythropoietin stimulating agents, new studies have demonstrated that administration of epoetin in accordance with the 2007 updated guidelines [19] translates in improvements in $\mathrm{Hb}$ outcomes [20, 21]. Moreover, it is been suggested that EB has the potential to prevent anemia and reduce transfusion requirements in patients with cancer receiving concomitant myelosuppressive chemotherapy [18, 22]. Nevertheless, few studies have examined the impact of EB to prevent anemia during neoadjuvant chemoradiotherapy in patients with digestive tract cancer [23].

Since most cancers may benefit from a combination of chemotherapy and radiotherapy, anemia may represent a crucial factor in order to obtain favorable clinical results in these patients [13]. Thus, the aim of the current study was to determine the efficacy and safety of epoetin-beta intervention to prevent moderate to severe anemia in patients with digestive tract tumors (esophagus/cardia or rectum) who were receiving concomitant chemoradiotherapy.

\section{Patients and methods}

This was a clinical prospective cohort study performed by the Galician Tumor Group [(Grupo Gallego de Tumores (GGT)] that aimed to determine the efficacy and safety of EB treatment and transfusion requirements in patients with neoadjuvant therapy prior to primary digestive tract tumor surgery.

\section{Patients}

Twenty-two patients were prospectively included 18 patients with rectal cancer and 4 with cancer of the esophagus/cardia. Rectal cancer staging included rectal digital exploration, chest $\mathrm{X}$-rays, abdominal and pelvic computed tomography (CT) scan, and echoendoscopy and/ or magnetic resonance imaging of the pelvis; while esophageal cancer was staged according to the thoracic and abdominal CT findings, esophagogastric transit and echoendoscopy. All patients were programmed for surgery, and only one case was considered inoperable.

Adult patients ( $\geq 18$ years), with Eastern Cooperative Oncology Group (ECOG) performance status (PS) $\leq 2$, and histologically confirmed malignancy were prospectively enrolled when their $\mathrm{Hb}$ baseline levels were $\leq 11 \mathrm{~g} / \mathrm{dL}$ with adequate iron levels (transferring saturation $>15 \%$, serum ferritin $>10 \mathrm{mg} / \mathrm{mL})$, folic acid $(>2 \mathrm{ng} / \mathrm{mL})$ and vitamin $\mathrm{B}_{12}(>200 \mathrm{pg} / \mathrm{mL})$, and life expectancy $>12$ weeks. Patients were excluded if they had received blood transfusion within the last 4 weeks, had been treated with epoetin within the last 8 weeks, presented hemorrhagic or iron-deficiency anemia, non-controlled hypertension, deepvenous thrombosis or severe arteriopathy.

\section{Treatment and assessments}

Anemia was defined as $\mathrm{Hb}$ levels $\leq 12 \mathrm{~g} / \mathrm{dl}$ as per current guidelines [19, 24]. From February 2006 to September 2007, patients who exhibited from moderate to severe anemia $(\mathrm{Hb} \leq 11 \mathrm{~g} / \mathrm{dl})$ at baseline were included and treated with a weekly dose of 30,000 IU of epoetin-beta (EB) (NeoRecormon ${ }^{\circledR}$, F Hoffman-La Roche Ltd, Basel, Switzerland) as a pre-filled syringe formulation until the hemoglobin level was $>12 \mathrm{~g} / \mathrm{dl}$. Other criteria for discontinuation included death, lost of follow-up, patient or investigator decision, more effective alternative, or any other on the best interest of the patient.

Iron supplementation was given at the discretion of the treating physician. Transfusions were given according to standard center practice. In two patients the dose was to be double after the first assessment $(60,000 \mathrm{IU} /$ week) also at physician judgment. 
Comparison was made of the mean $\mathrm{Hb}$ values $(\mathrm{mg} / \mathrm{dl})$ prior to EB treatment, half-way through radiochemotherapy (RT/CT) treatment, 4 weeks after completing RT/CT, the week before surgery, and postoperatively (approximately a week after surgery).

Downstaging and downsizing of the tumor were measured. Tumor regression grade (TRG) was quantitated in five grades TRG 1 (complete regression) showed absence of residual cancer and fibrosis extending through the different layers of the esophageal wall; TRG 2 was characterized by the presence of rare residual cancer cells scattered through the fibrosis; TRG 3 was characterized by an increase in the number of residual cancer cells, but fibrosis still predominated; TRG 4 showed residual cancer outgrowing fibrosis; and TRG 5 was characterized by absence of regressive changes [10]. Treatment toxicities and perioperative complications were recorded.

\section{Statistical analysis}

Data for quantitative variables were reported as the mean, typical error, standard deviation (SD) and $95 \%$ confidence interval $(95 \% \mathrm{CI})$, or as the median and IQR in the case of asymmetry. Comparison was made of the mean hemoglobin values overtime, based on analysis of variance for repeated measures (MANOVA).

\section{Results}

Patient characteristics and antitumoral therapy

Eighteen patients with rectal cancer and four patients with esophageal cancer received neo-adjuvant concomitant RT/ CT. They were a median of 68 years old and in general good condition as shown by their performance status (ECOG $<2,81.8 \%$ ) and the low number of chemotherapy cycles they received (median 1) (Table 1). All patients underwent concomitant radiochemotherapy. The median radiation dose was 5,040 (range 4,500-6,480) cGy. Chemotherapy consisted of fluoropyrimidines alone for two-thirds of the patients, meanwhile the rest were given fluoropyrimidines in combination with other agents (cisplatin or oxiplatin).

The tumor characteristics are summarized in Table 2. They were mostly graded as clinical stage II (13.6\%) and III $(81.8 \%)$, resulting in pathological stage I (31.8\%), II (27.3\%) and III (18.2\%) after treatment (Fig. 1a). Remarkably, four patients (18.2\%), two in clinical stage II and two in III, achieved complete pathological response. Only one patient presented an inoperable tumor.

Resection was performed a median of 57.5 days from the time of initial RT/CT (Table 1). The majority of
Table 1 Baseline characteristics of patients subjected to preoperative chemoradiotherapy

\begin{tabular}{|c|c|c|}
\hline Age & Median & Range \\
\hline Years & 68 & $49-79$ \\
\hline Gender & $n$ & $\%$ \\
\hline Male & 8 & 36.4 \\
\hline Female & 14 & 63.6 \\
\hline ECOG-PS & $n$ & $\%$ \\
\hline 0 & 1 & 4.5 \\
\hline 1 & 17 & 77.3 \\
\hline $1-2$ & 3 & 13.6 \\
\hline 2 & 1 & 4.5 \\
\hline Cycle of chemotherapy & $n$ & $\%$ \\
\hline 1 & 16 & 72.7 \\
\hline 2 & 3 & 13.6 \\
\hline $3-5$ & 3 & 13.6 \\
\hline Chemotherapeutic agent & $n$ & $\%$ \\
\hline $5 \mathrm{FU}$ & 14 & 63.6 \\
\hline $5 \mathrm{FU}+\mathrm{CDDP}$ & 5 & 22.7 \\
\hline UFT & 2 & 9.1 \\
\hline FOLFOX & 1 & 4.5 \\
\hline Radiotherapy & Median & Range \\
\hline Total dose (cGy) & 5,040 & $4,500-6,480$ \\
\hline Time from neoadjuvant therapy to resection & Median & IQR \\
\hline Days & 57.5 & $49.0-73.5$ \\
\hline
\end{tabular}

ECOG-PS eastern cooperative oncology group performance status, $5 F U$ 5-fluorouracil, $C D D P$ cisplatin, UFT tegafur-uracil, FOLFOX 5fluorouracil/leucovorin/oxaliplatin, $c G y$ centigray

patients underwent low anterior (45.5\%) or abdominoperineal $(27.3 \%)$ resections. Partial esophagogastrectomy was necessary in three patients (13.6\%), as were gastrectomy and colostomy in one patient each $(4.5 \%)$. Perioperatory complications during surgery and the month thereafter were uncommon (27.3\%), and consisted of infection of the wound in two patients, one rectovaginal fistula, one parastomal hernia, one case of ileum and one sepsis. There was no postoperative death (Table 3 ).

\section{Epoetin treatment}

Patients with $\mathrm{Hb}$ levels $\leq 11 \mathrm{~g} / \mathrm{dl}$ were recruited and received EB during neoadjuvant treatment and until surgery was completed. Assessments were done at pretreatment, half-way through concomitant RT/CT, 4 weeks after, the week prior to the resection of the tumor and approximately a week later. Notably, although the dose of EB needed to be transiently doubled in two patients, none of them were administered blood transfusions before or after surgery.

In the study, patients were affected with moderate to severe anemia, showing an average $\mathrm{Hb}$ of $10.12( \pm 0.19)$ 
Table 2 Tumor characteristics

\begin{tabular}{lll}
\hline & $n$ & $\%$ \\
\hline Tumor location & 17 & \\
Rectum & 2 & 77.3 \\
Esophagus & 2 & 9.1 \\
Cardias & 1 & 9.1 \\
Anal canal & & 4.5 \\
Clinical TNM stage & 3 & \\
II (cT3N0M0) & 11 & 13.6 \\
III (cT3N1M0) & 1 & 50.0 \\
III (cT3N2M0) & 5 & 4.5 \\
III (cT4N1M0) & 1 & 22.7 \\
III (cT4N2M0) & 1 & 4.5 \\
IV (cT3N2M1) & & 4.5 \\
Pathologic TNM stage & 4 & \\
0 (pT0N0M0) & 1 & 18.2 \\
I (pT1N0M0) & 6 & 4.5 \\
I (pT2N0M0) & 5 & 27.3 \\
II (pT3N0M0) & 1 & 22.7 \\
II (pT4N0M0) & 1 & 4.5 \\
III (pT0N2M0) & 2 & 4.5 \\
III (pT3N1M0) & 1 & 9.1 \\
III (pT3N2M0) & & 4.5 \\
Unresectable & & 4.5 \\
\hline
\end{tabular}

g/dl. Mean $\mathrm{Hb}$ change significantly throughout the RT/CT therapy being $12.32( \pm 0.24) \mathrm{g} / \mathrm{dl}$ at mid-treatment and $12.75( \pm 0.29) \mathrm{g} / \mathrm{dl} 4$ weeks after the end of RT/CT (Fig. 2). Total $\mathrm{Hb}$ variation during RT/CT was $2.63 \mathrm{~g} / \mathrm{dl}$. All contrasts in the differences in the mean $\mathrm{Hb}$ level at pretreatment and $\mathrm{Hb}$ levels during $\mathrm{RT} / \mathrm{CT}$ and until surgery proved significant $(p<0.001)$, and a trend was observed towards the assessment postsurgery $(p<0.073)$.

Mean preoperative $\mathrm{Hb}$ level was $12.54( \pm 0.36) \mathrm{g} / \mathrm{dl}$, whereas mean postoperative was $10.89( \pm 0.40) \mathrm{g} / \mathrm{dl}$, and there was a significant correlation between those values $(p<0.001)$. During surgery, mean $\mathrm{Hb}$ drop was $1.65 \mathrm{~g} / \mathrm{dl}$.

Levels of $\mathrm{Hb}$ were closely monitored and the patients discontinued EB treatment every time levels of $\mathrm{Hb}>12 \mathrm{~g} /$ dl were observed in their assessments. As a result no related toxicities were recorded. None of the patients were treated with EB after surgery.

Clinical outcome

Tumor regression was measured as a parameter of the effects of the neoadjuvant treatment on the resected tumor (Fig. 1b). Regressive changes were present in all patients. Most (54.6\%) showed good response to neoadjuvant
Fig. 1 Tumor characteristics and outcomes. a Percentage of patients in clinical and pathological stages. $\mathbf{b}$ Percentage of patients in tumor regression graded as TRG 1 , complete regression; TRG 2, rare residual cancer cells; TRG 3 , some residual cancer cells but fibrosis still predominated; TRG 4 , residual cancer outgrowing fibrosis. c Percentage of patients showing downsizing. d Percentage of patients showing downstaging

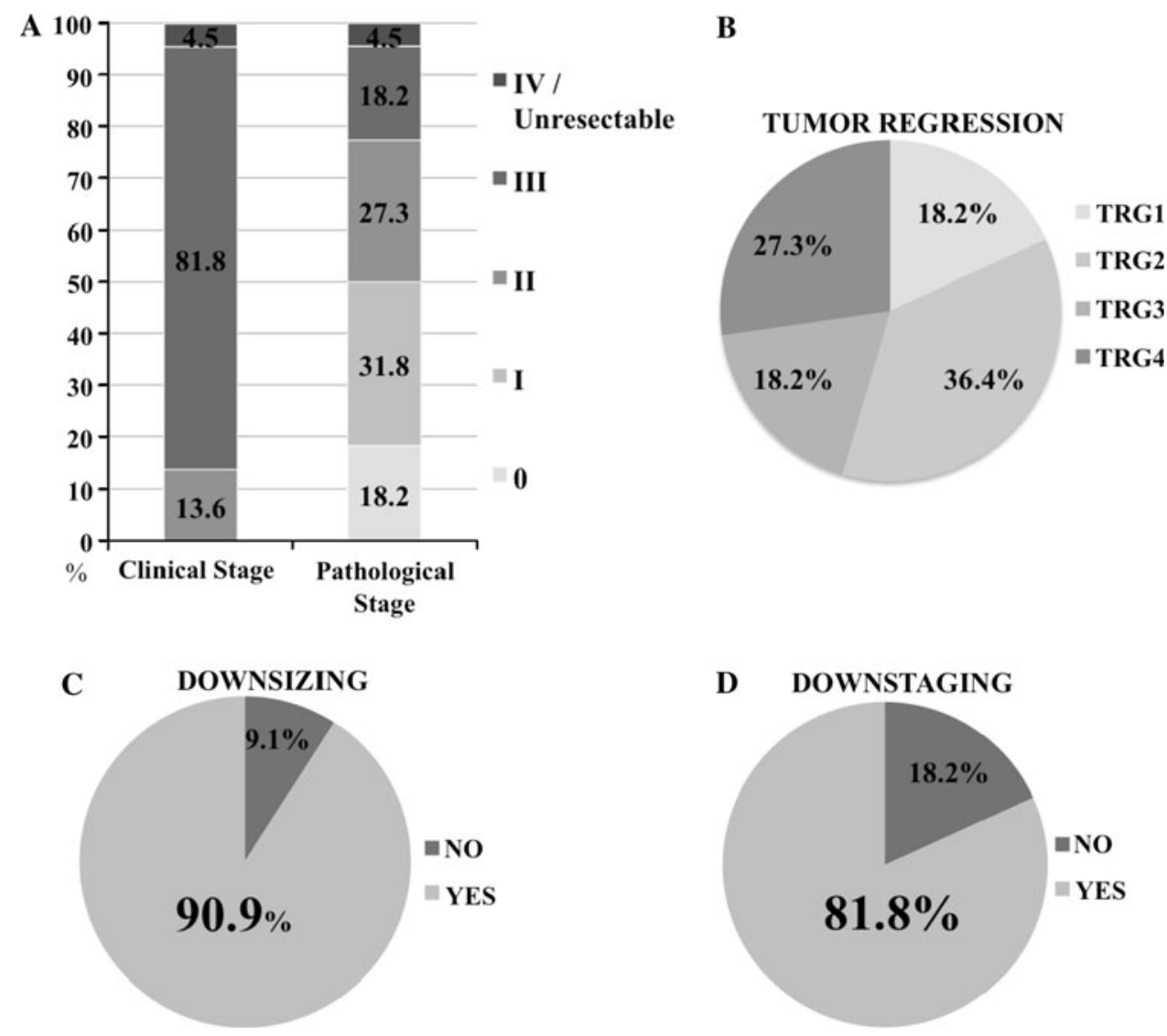


Table 3 Surgery and complications

\begin{tabular}{lll}
\hline Time from neoadjuvant therapy to resection & Median & IQR \\
\hline Days & 57.5 & $49.0-73.5$ \\
Type of resection & $n$ & $\%$ \\
Low anterior & 10 & 45.5 \\
Abdominoperineal & 6 & 27.3 \\
Partial esophagogastrectomy & 3 & 13.6 \\
Gastrectomy & 1 & 4.5 \\
Colostomy & 1 & 4.5 \\
Hartmann resection & 1 & 4.5 \\
Surgical complications & $n$ & $\%$ \\
No complications & 16 & 72.7 \\
Post-operative wound infection & 2 & 9.1 \\
Rectovaginal fistula & 1 & 4.5 \\
Parastomal hernia & 1 & 4.5 \\
Ileum & 1 & 4.5 \\
Sepsis & 1 & 4.5 \\
\hline
\end{tabular}

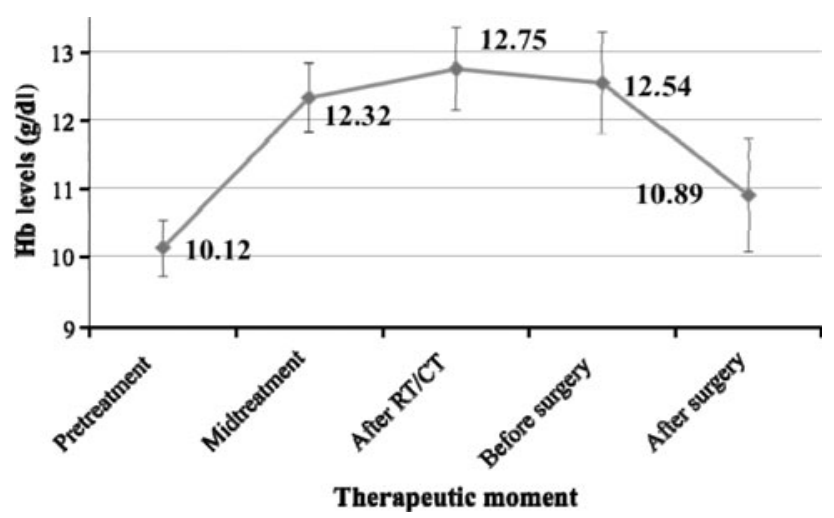

Fig. 2 Effect of epoetin-beta on mean hemoglobin $(\mathrm{Hb})$ levels in patients undergoing neoadjuvant chemotherapy against digestive tract tumors. Error bars $95 \%$ CI

treatment in the surgically removed tissues (TRG 1-2), meanwhile less than half had residual cancer, whether or not outgrowing fibrosis (TRG 3-4). Most importantly, almost one in five patients attained complete regression of their tumors (TRG 1) (Fig. 1b).

These data were confirmed by the downstaging and downsizing values recorded after the neoadjuvant treatment (Fig. 1c, d). A total of $18(81.8 \%)$ patients reduced their tumor stage and 20 (90.9\%) decreased their tumoral mass. The mean downsizing was $3.6 \mathrm{~cm}(p<0.001)$, from 5.9 to $2.3 \mathrm{~cm}$ of average. No T-level upstaging was evident in this study.

Consequently, at the time of the last assessment on April 2008, 21 patients were alive, $18(81.8 \%)$ were free of the disease, one had stable disease $(4.5 \%)$ and two $(9.1 \%)$ exhibited progressive disease. One patient had died due to chemotherapic drug toxicity.

\section{Conclusion}

Correction of anemia is advisable since the measure of pretreatment of low $\mathrm{Hb}$ level maybe a prognostic factor for rectal cancer patients undergoing neoadjuvant RT/CT and it is a modifiable factor [13].

In our series, EB treatment avoided the need of blood transfusion, which by itself increases the risk of developing postoperative problems [12]. Moreover, treatment with EB was able to elude preoperative anemia in patients with levels of $\mathrm{Hb} \leq 11 \mathrm{~g} / \mathrm{dl}$ without greatly interfering in the rate of surgical complications usually encountered in this setting, either in alpha-epoetin-treated patients (16\%) [25] or regardless of hematopoietic correction $(27.7-31.2 \%)$ $[26,27]$.

The reduction in the tumor stage by a full course of radiotherapy plus chemotherapy becomes evident in the histological changes of the tumor samples. The Mandard's classification is been widely used as a regression system and is been shown to predict local failure, disease-free survival, and overall survival $[10,27,28]$. The complete pathological response (18.2\%) recorded in this study in patients with corrected anemia is slightly higher than that obtained with a similar dose of radiotherapy and fluoropyrimidine-based chemotherapy before surgery in advance rectal cancer, regardless of hemoglobin levels (14.2\%) [27]. As for the percentage of good responses (54.5\%), which includes Mandard TGR 1-2, it is superior to that of preoperative approaches in esophageal $(42.0 \%)$ and rectal cancer (20-31.0\%) [9, 10, 27-29].

In fact, a closer insight on the effects on anemia correction on neoadjuvant therapy supported that non-anemic patients significantly achieved not only better tumor response than anemic patients as per rectal cancer regression rate scale ( 55 vs. $28 \%$ ), but also higher rate of complete pathological responses (19 vs. $4 \%$ ), and downstaging (55 vs. $16 \%$ ) [14].

The short course of radiotherapy and addition of 5FUbased antitumor drugs often result in downstaging or downsizing of digestive tract tumors that, in turn, increase the rate of curative resection and reduce locoregional failure [30-32]. While other studies in rectal cancer patients with chemoradiation showed a downstaging rate between 43.5 and $60.4 \%$ [26, 27, 33], in the present study, a remarkable $81.8 \%$ of the patients reduced their tumor stage, which correlated with a significant shrinking of the tumor $(90.9 \%)$. Therefore, EB treatment of these patients does not seem to promote tumor growth when anemia correction is achieved following current guidelines.

Resection is typically performed 6 weeks after completion of radiotherapy. Further delay leading to increased downsizing [34], which may be relevant to the present results in which the median time was of around 8 weeks. 
We speculate that the good clinical outcome we observed maybe a consequence of the tumor regression rates and downstaging observed, as they have been proposed as prognostic factors for disease-free survival and better tumor control [27]; however, the brief follow-up period does not allow to conclude on the tumor locoregional control or survival data.

Despite the encouraging results, this study sustained two main difficulties. First, the small size of the sample and, secondly, a heterogeneous patient population bearing various tumors and undergoing different chemotherapy regimens. Also, an assessment of the QoL was not carried out because of the short length of the neoadjuvant treatment, as well as due to the later referral of patients for surgery, which would hinder the analysis of such evaluation. However, we believe it may provide an overview on the efficacy and security of $\mathrm{EB}$ in patients with digestive malignancies subjected to neoadjuvant fluoropyrimidineor platinum-based radiochemotherapy.

Similarly, although iron metabolism parameters (serum ferritin, serum iron, transferrin saturation index) were tested in all patients before inclusion, it is also possible that some of them may have presented a type of anemia unrelated to the chemotherapy treatment. On the other hand, we speculate that EB does not promote tumor growth; nevertheless, the results cannot demonstrate the impact of the anemia correction on the efficacy of the neoadjuvant treatment. Moreover, anemia correction and efficacy may be independent events. Finally, the absence of erythropoietin-related adverse events is noteworthy. Thus, in summary, EB treatment in our series of patients with digestive malignancies subjected to neoadjuvant radiochemotherapy proved effective and safe, avoiding the need for transfusion during surgery. Moreover, in this series of patients, anemia correction had no negative effects over tumor downstaging or downsizing. Therefore, we suggest that the use of erythropoietin in support of a preoperative radiochemotherapy regimen for these patients should be considered.

Acknowledgments We gratefully acknowledge the assistance of Dr Cristina Fernández for statistical data analysis and Carlos Lisbona (LIDESEC SL) for providing medical writing and editing services. This study was supported by F. Hoffmann-La Roche Ltd. The trial was designed, implemented and overseen by Dr Antonio Gómez Caamaño. The sponsor assisted in the collection and analysis of data. Responsibility for opinions, conclusions and interpretation of data lies with the authors.

Conflict of interest statement Antonio Gómez, Mercedes Salgado, Manuel Valladares-Ayerbes, Mónica Jorge, Ana Carballo, Sonia Candamio, Pilar Izquierdo and Rafael López do not have any financial interests, such as stock ownership, or employment for any company. Antonio Gómez and Ana Carballo received remuneration from Roche Farma S.A., Manuel Valladares-Ayerbes had a consultant/advisory role with Amgen and Merck. Rafael López received funding from Sanofi Aventis, Pfizer and Almirall. Mercedes Salgado,
Mónica Jorge, Sonia Candamio, Pilar Izquierdo and Enrique Castro have nothing to disclosure.

\section{References}

1. Groopman JE, Itri LM (1999) Chemotherapy-induced anemia in adults: incidence and treatment. J Natl Cancer Inst 91:1616-1634

2. Ludwig H, Van Belle S, Barrett-Lee P, Birgegard G, Bokemeyer C, Gascon P, Kosmidis P, Krzakowski M, Nortier J, Olmi P, Schneider M, Schrijvers D (2004) The European Cancer Anaemia Survey (ECAS): a large, multinational, prospective survey defining the prevalence, incidence, and treatment of anaemia in cancer patients. Eur J Cancer 40:2293-2306

3. Tas F, Eralp Y, Basaran M, Sakar B, Alici S, Argon A, Bulutlar G, Camlica H, Aydiner A, Topuz E (2002) Anemia in oncology practice: relation to diseases and their therapies. Am J Clin Oncol 25:371-379

4. Cella D, Dobrez D, Glaspy J (2003) Control of cancer-related anemia with erythropoietic agents: a review of evidence for improved quality of life and clinical outcomes. Ann Oncol 14:511-519

5. Caro JJ, Salas M, Ward A, Goss G (2001) Anemia as an independent prognostic factor for survival in patients with cancer: a systemic, quantitative review. Cancer 91:2214-2221

6. Knight K, Wade S, Balducci L (2004) Prevalence and outcomes of anemia in cancer: a systematic review of the literature. Am J Med 116(Suppl 7A):11S-26S

7. Sebag-Montefiore D, Stephens RJ, Steele R, Monson J, Grieve R, Khanna S, Quirke P, Couture J, de Metz C, Myint AS, Bessell E, Griffiths G, Thompson LC, Parmar M (2009) Preoperative radiotherapy versus selective postoperative chemoradiotherapy in patients with rectal cancer (MRC CR07 and NCIC-CTG C016): a multicentre, randomised trial. Lancet 373:811-820

8. Sauer R, Becker H, Hohenberger W, Rodel C, Wittekind C, Fietkau R, Martus P, Tschmelitsch J, Hager E, Hess CF, Karstens JH, Liersch T, Schmidberger H, Raab R (2004) Preoperative versus postoperative chemoradiotherapy for rectal cancer. N Engl J Med 351:1731-1740

9. Rodel C, Martus P, Papadoupolos T, Fuzesi L, Klimpfinger M, Fietkau R, Liersch T, Hohenberger W, Raab R, Sauer R, Wittekind C (2005) Prognostic significance of tumor regression after preoperative chemoradiotherapy for rectal cancer. J Clin Oncol 23:8688-8696

10. Mandard AM, Dalibard F, Mandard JC, Marnay J, Henry-Amar M, Petiot JF, Roussel A, Jacob JH, Segol P, Samama G et al (1994) Pathologic assessment of tumor regression after preoperative chemoradiotherapy of esophageal carcinoma. Clinicopathologic correlations. Cancer 73:2680-2686

11. Lee SH, Lee KC, Choi JH, Oh JH, Baek JH, Park SH, Shin DB (2008) Chemoradiotherapy followed by surgery in rectal cancer: improved local control using a moderately high pelvic radiation dose. Jpn J Clin Oncol 38:112-121

12. Voelter V, Schuhmacher C, Busch R, Peschel C, Siewert JR, Lordick F (2004) Incidence of anemia in patients receiving neoadjuvant chemotherapy for locally advanced esophagogastric cancer. Ann Thorac Surg 78:1037-1041

13. Berardi R, Braconi C, Mantello G, Scartozzi M, Del Prete S, Luppi G, Martinelli R, Fumagalli M, Valeri G, Bearzi I, Marmovale C, Grillo-Ruggieri F, Cascinu S (2006) Anemia may influence the outcome of patients undergoing neo-adjuvant treatment of rectal cancer. Ann Oncol 17:1661-1664

14. Box B, Lindsey I, Wheeler JM, Warren BF, Cunningham C, George BD, Mortensen NJ, Jones AC (2005) Neoadjuvant 
therapy for rectal cancer: improved tumor response, local recurrence, and overall survival in nonanemic patients. Dis Colon Rectum 48:1153-1160

15. Glimelius B, Linne T, Hoffman K, Larsson L, Svensson JH, Nasman P, Svensson B, Helmers C (1998) Epoetin beta in the treatment of anemia in patients with advanced gastrointestinal cancer. J Clin Oncol 16:434-440

16. Suzuki Y, Tokuda Y, Fujiwara Y, Minami H, Ohashi Y, Saijo N (2008) Weekly epoetin beta maintains haemoglobin levels and improves quality of life in patients with non-myeloid malignancies receiving chemotherapy. Jpn J Clin Oncol 38:214-221

17. Strauss HG, Haensgen G, Dunst J, Hayward CR, Burger HU, Scherhag A, Koelbl H (2008) Effects of anemia correction with epoetin beta in patients receiving radiochemotherapy for advanced cervical cancer. Int J Gynecol Cancer 18:515-524

18. Pronzato P, Jassem J, Mayordomo J (2006) Epoetin beta therapy in patients with solid tumours. Crit Rev Oncol Hematol 58:46-52

19. Bokemeyer C, Aapro MS, Courdi A, Foubert J, Link H, Österborg A, Repetto L, Soubeyran P (2007) EORTC guidelines for the use of erythropoietic proteins in anaemic patients with cancer: 2006 update. Eur J Cancer 43:258-270

20. Aapro M, Van Erps J, MacDonald K, Soubeyran P, Muenzberg M, Turner M, Warrinnier H, Albrecht T, Abraham I (2009) Managing cancer-related anaemia in congruence with the EORTC guidelines is an independent predictor of haemoglobin outcome: initial evidence from the RESPOND study. Eur $\mathbf{J}$ Cancer 45:8-11

21. Aapro MS, Birgegard G, Bokemeyer C, Cornes P, Foubert J, Gascon P, Glaspy J, Hellstrom-Lindberg E, Link H, Ludwig H, Osterborg A, Repetto L, Soubeyran P (2008) Erythropoietins should be used according to guidelines. Lancet Oncol 9:412-413

22. Cheer SM, Wagstaff AJ (2004) Epoetin beta: a review of its clinical use in the treatment of anaemia in patients with cancer. Drugs 64:323-346

23. Salgado M, Gómez A, Valladares M, Jorge M, Carballo A (2008) Efficacy of epoetin-beta 30,000 iu/week in correcting anemia in patients with gastrointestinal tumors subjected to concomitant chemo-radiotherapy. In: ASCO. Gastrointestinal cancers symposium. Category: Colon and rectum-multidisciplinary treatment, abstract no: 517

24. Rizzo JD, Somerfield MR, Hagerty KL, Seidenfeld J, Bohlius J, Bennett CL, Cella DF, Djulbegovic B, Goode MJ, Jakubowski AA, Rarick MU, Regan DH, Lichtin AE (2008) Use of epoetin and darbepoetin in patients with cancer: 2007 American Society of Clinical Oncology/American Society of Hematology clinical practice guideline update. J Clin Oncol 26:132-149
25. Abbrederis K, Bassermann F, Schuhmacher C, Voelter V, Busch R, Roethling N, Sendler A, Siewert JR, Peschel C, Lordick F (2006) Erythropoietin-alfa during neoadjuvant chemotherapy for locally advanced esophagogastric adenocarcinoma. Ann Thorac Surg 82:293-297

26. Chao M, Gibbs P, Tjandra J, Cullinan M, McLaughlin S, Faragher I, Skinner I, Jones I (2005) Preoperative chemotherapy and radiotherapy for locally advanced rectal cancer. ANZ J Surg 75:286-291

27. Suarez J, Vera R, Balen E, Gomez M, Arias F, Lera JM, Herrera J, Zazpe C (2008) Pathologic response assessed by Mandard grade is a better prognostic factor than down staging for diseasefree survival after preoperative radiochemotherapy for advanced rectal cancer. Colorectal Dis 10:563-568

28. Vecchio FM, Valentini V, Minsky BD, Padula GD, Venkatraman ES, Balducci M, Micciche F, Ricci R, Morganti AG, Gambacorta MA, Maurizi F, Coco C (2005) The relationship of pathologic tumor regression grade (TRG) and outcomes after preoperative therapy in rectal cancer. Int J Radiat Oncol Biol Phys 62:752-760

29. Bouzourene H, Bosman FT, Seelentag W, Matter M, Coucke P (2002) Importance of tumor regression assessment in predicting the outcome in patients with locally advanced rectal carcinoma who are treated with preoperative radiotherapy. Cancer 94:11211130

30. Kapiteijn E, Marijnen CA, Nagtegaal ID, Putter H, Steup WH, Wiggers T, Rutten HJ, Pahlman L, Glimelius B, van Krieken JH, Leer JW, van de Velde CJ (2001) Preoperative radiotherapy combined with total mesorectal excision for resectable rectal cancer. N Engl J Med 345:638-646

31. No_authors_listed (1997) Improved survival with preoperative radiotherapy in resectable rectal cancer. Swedish rectal cancer trial. N Engl J Med 336:980-987

32. Benzoni E, Intersimone D, Terrosu G, Bresadola V, Cojutti A, Cerato F, Avellini C (2006) Prognostic value of tumor regression grading and depth of neoplastic infiltration within the perirectal fat after combined neoadjuvant radiochemotherapy and surgery for rectal cancer. J Clin Pathol 59:505-512

33. Das P, Skibber JM, Rodriguez-Bigas MA, Feig BW, Chang GJ, Wolff RA, Eng C, Krishnan S, Janjan NA, Crane CH (2007) Predictors of tumor response and downstaging in patients who receive preoperative chemoradiation for rectal cancer. Cancer 109:1750-1755

34. Tran CL, Udani S, Holt A, Arnell T, Kumar R, Stamos MJ (2006) Evaluation of safety of increased time interval between chemoradiation and resection for rectal cancer. Am J Surg 192:873-877 